\title{
Evaluation of the Beliefs of Parents in Iran about How to Care for Children During Dental Visits
}

\author{
Elham Farokh Gisour ${ }^{1} *$ and Arash Bigdeli ${ }^{2}$ \\ ${ }^{1}$ Pediatric Department, Kerman Dental University, Kerman, Iran \\ ${ }^{2}$ Kerman Dental Faculty, Iran
}

\begin{abstract}
Parents play an important role in their children's dental care and in their behavior during dental visits. Separating children from their parents during dental visits has been a challenging subject of debate for many years. Therefore, this study aims to evaluate parents' attitudes about being present during their children's visits to the dentist. The subjects for this cross-sectional study included 340 Iranian parents of five-10-year-old children who had been referred to dental clinics in Kerman, Iran. For this study, the parents of these children completed self-administered questionnaires. Results showed that 218 parents $(64.1 \%)$ agreed with leaving the practice room during their child's treatment, while $122(35.9 \%)$ did not agree. The main reason expressed by $41.3 \%$ of the parents for leaving the practicing room was that the dentist would be better able to control the child if they were alone. Another reason, cited by $16.5 \%$ of the parents, was not wanting to see their child suffering, and $42.2 \%$ said they believed that their child would be better treated if they were not present. Most parents who were in agreement with leaving the practice room while their child was receiving dental care felt this would lead to a better treatment outcome.
\end{abstract}

Keywords: Parent, pediatric dentistry, dental practice room.

\section{INTRODUCTION}

Parents play an important role in their children's dental care and in their behavior during dental visits. Parents are aware of their children's interests and worries. Most parents prefer to stay with their children during painful dental treatment and many children ask their parents to accompany them during their dental visits [1].

Separating children from their parents during dental visits has been discussed for many years. There are different views among dentists about the advantages and disadvantages of the parental presence during their children's visits to the dentist $[2,3]$.

Most dentists believe that separating children from their parents will eliminate many behavioral problems during the course of treatment. However, some dentists would prefer to treat children while their parents are present beside them. A number of dentists choose the method of separating children, but allow exceptions in certain circumstances [4]. The presence or absence of parents during their children's dental visits is addressed in the guidelines of the American Academy of Pediatric Dentistry for behavior modification [5].

Keeping parents out of the practice room can be useful for improving a child's behavior. Starkey et al. is one of the main supporters of separating children from their parents during treatment. However, dentists use a variety of methods to control children's behavior, and the presence of parents during pediatric dental treatment helps children to relax [4].

*Address correspondence to this author at the Pediatric Department, Kerman Dental University, Kerman, Iran; P-O-Box: 76175;

Tel: +98-9151689178; Fax: +98-341-2118073;

E-mail: e_1379farokh@yahoo.com
Dentists may have to prepare parents for their roles as part of the team working to attain the positive behavior of the child. Although the parents belong to this care-giving team, they may also keep a low profile as "silent observers" [6].

Abushal et al. analyzed a questionnaire, answered by 505 parents, where $97 \%$ preferred to stay with their children during dental visits. Most of the parents wishing to accompany their child (83\%) believed the child would feel safer [7].

Whatever decision is taken, it should be clearly explained to the parent in order to avoid miscommunication and parental dissatisfaction. The decision to include the parent should be based on the ultimate goal of achieving the positive behavior of the child and delivering safe and high-quality dental treatment [8].

This issue is important for dentists, in terms of both wasting time and losing control of a child they are treating. It is also important for their patients and parents. Both the parents and the children, either apart or together, may experience considerable anticipation and anxiety, which may cause the dentist to lose control and fail to provide appropriate treatment. Therefore, this study has aimed to evaluate parents' and dentists' attitudes towards the presence of parents during their children's dental visits.

\section{MATERIALS AND METHODOLOGY}

The subjects of this cross-sectional study were 340 Iranian parents of five-10-year-old children who had been referred to dental clinics in Kerman, Iran. The parents were selected systematically. A self-administered questionnaire was designed for them to answer. The questionnaire had four sections, with closed questions. Section one included demo- 
Table 1. The Distribution of the Parents' Opinion to Leave the Operatory According to the Age of the Child (Ranged Between 5 to 10, Range=5)

\begin{tabular}{|c|c|c|c|}
\hline Child Age (years) & N & Agreed to Leave the Operatory (\%) & Disagreed to Leave the Operatory (\%) \\
\hline \hline 5 & 70 & 57.1 & 42.9 \\
\hline 6 & 96 & 68.8 & 31.3 \\
\hline 7 & 54 & 77.8 & 22.2 \\
\hline 8 & 56 & 53.6 & 46.4 \\
\hline 10 & 46 & 56.5 & 43.5 \\
\hline Total & 18 & 17.8 & 22.2 \\
\hline
\end{tabular}

Table 2. The Frequency of Parents by Previous Experience and their Attitude Regards Leaving the Operatory

\begin{tabular}{|c|c|c|c|}
\hline Previous Experience & N & Agree with Leaving the Operatory (\%) & Disagree with Leaving the Operatory (\%) \\
\hline \hline Had no problem & 272 & 64.7 & 35.3 \\
\hline Had bad experience & 38 & 47.4 & 52.6 \\
\hline Intolerable & 22 & 81.1 & 18.2 \\
\hline Have no experience & 8 & 75 & 25 \\
\hline Total & 340 & 218 & 122 \\
\hline
\end{tabular}

graphic information about the child (age, sex and birth order). Section two asked about the relationship of the person accompanying the child (mother or father), their educational level and their experience in terms of familiarity with dental services. The third section gathered information about the parents' attitudes towards their presence in a practice room during their children's treatment and the fourth included the dentist's attitude regarding the presence of parents in the practice room during their child's treatment. The collected data were analyzed using the SPSS program, version 10 . The Chi-square test was used to determine the difference between various variables, and the $\mathrm{P}$-value was set as $<0.05$ for significance.

In this study, 340 questionnaires were answered by 340 parents of five-10-year-old children, who had been referred for dental services for the first time. The mean age range of the children was $6.9 \pm 1.5$ years; $172(50.6 \%)$ of them were males and $168(49.4 \%)$ were females.

\section{RESULTS}

One third, or 108 (31.8\%), of the accompanying parents were fathers and $232(68.2 \%)$ were mothers of the children. The educational levels they reported were $15.3 \%$ with less than diploma, $45.9 \%$ with diploma and $38.8 \%$ with higher education.

Most of the parents $(80 \%)$ had not experienced any problems in previous meetings with a dentist. However, $11.2 \%$ had had bad experiences, $6.5 \%$ reported having had unbearable experiences and $2.3 \%$ of them had never had a meeting with a dentist. Two-thirds of the parents, or 218 (64.1\%), agreed to leave the practice room during their child's treatment and 122 (35.9\%) did not agree. About 46.5\%, 29.4\%, $14.7 \%, 6.5 \%$ and $2.9 \%$ of the children were first, second, third, fourth and fifth in birth order, respectively.

The main reason expressed by $41.3 \%$ of parents who left the practicing room was that the dentist would be better able to control the child if they were alone. Another reason, cited by $16.5 \%$ of the parents, was not wanting to see their child suffering, and $42.2 \%$ said they believed that without their presence the child would receive better treatment.

Of the parents who disagreed with leaving the room, $88.5 \%$ wanted to see how the dentist behaved with their child, $8.2 \%$ wanted to help the dentist to control their child and $3.3 \%$ wanted to be there to answer the dentist's questions.

Parents' opinions about leaving the practicing room differed significantly, depending on the age of their child (Pvalue <0.05) (Table 1). The opinions of mothers about leaving the practicing room were also significantly different, according to their educational levels $(p<0.05)$. However, there was no difference between the preferences of male or female parents in accompanying their children $(\mathrm{p}=0.10)$, nor in their preferences in terms of male or female children $(p=0.95)$. Table 1 indicates that the frequency of patients decreased with age.

There was a significant difference between the previous experiences of the parents and their belief about leaving the practicing room $(\mathrm{p}<0.05)$ (Table 2$)$, but there was no relationship between parents' attitudes about leaving the practicing room and the birth order of their child $(\mathrm{p}=0.41)$ (Table 3).

\section{DISCUSSION}

The main finding of this study was that many of these Iranian parents agreed to leave the practicing room during their child's treatment. This finding agrees with the other studies undertaken in different countries [1, 7, 9 and 10].

Most of the parents $(80 \%)$ had not had any problems in a previous visit to a dentist. The proportion of these, in the previous study by Abushal et al. [7], was 94\%.

In our study, $45 \%$ of parents had a diploma level of education, compared to $37.4 \%$ in the Abushal et al. study [7]. In several other studies, including those by Abushal et al. [7] in Saudi Arabia, Peretz et al. [11] in Israel, Crowley et al. [10] in Ireland, and Kamp et al. [1] in Germany, most of the parents expressed a wish to be present in the practicing room. 
Table 3. The frequency of the Parents by the Child Birth Rank and their Attitude Regards Leaving the Operatory

\begin{tabular}{|c|c|c|c|}
\hline Previous Experience & $\mathbf{N}$ & Agree with Leaving the Operatory $(\%)$ & Disagree with Leaving the Operatory $(\%)$ \\
\hline \hline Firth birth & 158 & 68.4 & 31.6 \\
\hline Second birth & 100 & 58 & 42 \\
\hline Third birth & 50 & 64 & 36 \\
\hline Fourth birth & 22 & 63.6 & 36.4 \\
\hline Fifth birth & 10 & 60 & 40 \\
\hline Total & 340 & 64.1 & 35.9 \\
\hline
\end{tabular}

By contrast, most of the parents in our study agreed to leave the practicing room. In another study conducted by Razavi et al. [12] in Qazvin, Iran, all of the parents agreed to leave the practicing room during their child's dental visit, which is comparable to our study.

In the present study, $35.9 \%$ of the parents disagreed with leaving the practicing room; most of them wanted to see how the dentist behaved with their child. This was different from the study by Abushal et al. [7], in which the main reason for parents wishing to accompany their child was so that he or she would feel safe $(83 \%)$.

In the study by Kamp et al. [1], of the $34 \%$ of parents who did not wish to be present in the practicing room, the main reason given by $82 \%$ of them was that their child was old enough to receive treatment alone and $63 \%$ felt that their presence might make the child misbehave. The study by Peretz et al. [11] showed that the main reason most parents wished to accompany their child was that the dentist would not succeed in managing the child.

It seems that parental attitudes about parents' willingness to stay with their children during dental treatment depends on the educational level, social culture, lifestyle, previous experiences and how much the parents trust the dentist, although the present study in Kerman found a significant difference between parents' educational levels and their willingness to stay at the practicing room $(\mathrm{p}<0.05)$.

\section{CONCLUSION}

Most Iranian parents preferred to leave the practicing room during their children's visits to the dentist. The main reason given by the parents who left the practicing room was that the child would behave better without their presence. Most of the parents who agreed to leave the practice room during their child's dental visit felt this would lead to better a treatment outcome.

\section{ACKNOWLEDGEMENTS}

The author wishes to acknowledge the help of Mr. Arash Bigdeli in data collection.

\section{CONFLICT OF INTEREST}

None declare.

\section{SUPPLEMENTARY MATERIAL}

Supplementary material is available on the publisher's web site along with the published article.

\section{REFERENCES}

[1] Kamp AA. Parent child separation during dental care: a survey of parent's preference. Pediatr Dent 1992; 14(4): 231-5.

[2] Molinari GE, DeYoung AK. Non pharmacologic behavior management techniques used with pediatric dental patients. J Mich Dent Assoc 2002; 84(1): 30-3.

[3] Molinari GE, DeYoung AK. Parental presence and absence as a behavior management technique. J Mich Dent Assoc 2004; 86(1): 30-3.

[4] Wright DZ, Starkey PE, Cardner DE, Parent - child separation, in Managing childrens behavior in the dental office, CV Mosby Co. 1983 ; pp. 57-74.

[5] American Academy of Pediatric Dentistry Clinical Affairs Committee: Behavior Management Subcomittee; American Academy of Pediatric Dentistry Council on Clinical Affairs: Committee on Behavior Guidance. Guideline on behavior guidance for the pediatric dental patient. Pediatr Dent 2005-2006; 27 (7 Suppl): 92-100.

[6] Piira T, Sugiura T, Champion GD, Donnelly N, Cole ASJ. The role of parental presence in the context of children's medical procedures: a systematic review. Child Care Health Dev 2005; 31(2): 233-43.

[7] Abushal M, Adenubi JO. Attitudes of Saudi parents toward separation from their children during dental treatment. Saudi Dent J 2009; 21: 63-7.

[8] Parashar V. Parental presence during their Childs dental treatment. J Oral Health Comm Dent 2010; 4(3): 52-4.

[9] Arathi R, Ashwini R. Parental presence in the dental operatory parent's point of view. J Indian Soc Pedod Prev Dent 1999; 17(4): $150-5$.

[10] Crowley E, Whelton H, O'Mullane D, et al. Parents' preference as to whether they would like to accompany their child when receiving dental treatment - results from a national survey. J Irish Dent Assoc 2005; 51(1): 23-24.

[11] Peretz B, Glaicher H, Ram D. Child-Management Techniques. are there differences in the way female and male pediatric dentists in Israel practice? Braz Dent J 2003; 14(2): 82-6.

[12] Razavi Sh, Purtaji B. Determining the behavior management techniques acceptance of mothers referred to the department of pediatric dentistry in Qaznin. JQUMS 2009; 13(3): 81-6. 